\title{
Permanent? Ageless? A Case Study of the Pulitzer Arts Foundation in St. Louis
}

\author{
LIANE HANCOCK \\ University of Louisiana Lafayette
}

\begin{abstract}
This paper endeavors to relate the ongoing preservation and adaptability of the Pulitzer Arts Foundation to observations on how permanence is viewed within the built environment both in Japan and the United States. It presents best practice protocols for both preservation and maintenance including measures that were taken during construction to ensure the building would remain ageless.
\end{abstract}

\section{INTRODUCTION}

In 2001, the Pulitzer Foundation for the Arts opened in St. Louis. Designed by Tadao Ando, it was a new landmark in a beleaguered portion of the city, a veritable monument to reinforced concrete. The dream was that it would act as catalyst to revitalize the Grand Avenue Arts district. For Tadao Ando, it was an opportunity to introduce himself to the international stage, and to continue to build a reputation in his home country. At the same time, the owner, Emily Rauh Pulitzer, had not yet decided exactly how her new institution would operate.

Comprehending the significance of this new building as an illustration of Tadao Ando's expertise, the design and construction team developed systematized preservation methods even as the building's walls were being poured. The intent: to keep the building forever young. At the same time, the open ended nature of Ando's design process meant the design and construction team incorporated redundancy for the internal infrastructure of the building, a method that would later prove valuable as the Pulitzer's programming and use changed. Finally, the decision to select the project superintendent as facilities manager allowed the laboratory-like atmosphere created during construction to carry over into maintaining the building.

In order to frame this narrative properly, it is necessary to begin with observations on how permanence is viewed within the built environment both in Japan and the United States.

\section{JAPANESE CULTURE OF RENEWAL ACROSS THE BUILT ENVIRONMENT}

Writings about Tadao Ando emphasize attentive care and craft, and a minimalist yet materially rich aesthetic. Within the narrative of contemporary architecture, his buildings' importance seem fundamentally cast in stone. It is difficult, then, to conceptualize that culturally the Japanese see the built landscape as fleeting and largely disposable. Japan's constant razing and reconstruction is widely referred to as a scrap and build economy. The Economist states "The value of the average Japanese house depreciates to zero in 22 years." ${ }^{11}$ The Japan Times asserts that this deprecation originates as "a function of the government's plan to keep the economy humming with a constant need for residential construction." ${ }^{2}$

The result is a construction industry that builds disposable architecture emphasizing planned obsolescence. Benefits of this short-term construction cycle is that the built environment is consistently and constantly upgraded to include the newest efficiencies in energy and water use, and to utilize new materials, fixtures, and infrastructural upgrades.

The environment itself facilitates this reconstruction - the unstable ground of this seismically active region makes the relative permanence of masonry construction illogical, and instead historically emphasized lightweight and easily rebuilt construction. As greater communication with the west occurred, Japan benefited from the introduction of reinforced concrete, a western material that could resist seismic and environmental threat. It quickly and fundamentally changed the building fabric of the country. However, increased earthquake requirements have superseded concrete's relative permanence.

As reported in Japan Times "In 1981, following a massive earthquake in Miyagi Prefecture, quake-proofing standards were made stricter so that new buildings would be able to withstand temblors of up to 7 on the Japanese seismic scale... Since the Great East Japan Earthquake on March 11, 2011, both the central and local governments have promoted quake-proofing of existing buildings, but the response has been poor, despite the fact that some local governments, such as Tokyo's Toshima Ward, mandate the improvements under penalty of law." ${ }^{\prime 3}$ The article explains rather than retrofit buildings it is simply more cost effective to implement advancements in seismic technology through new construction by adding units or amenities to cover the cost of inflation and construction.

The scrap and build economy encompasses residential, retail, and commercial buildings. What is relatively new to the Japanese built environment are museums and programs for community based activities. Prior to World War II the monarchy provided very few public amenities for the Japanese populace; now greater interest in preserving culture, in addition to a growing emphasis on nationalism, has increased the desire for public typologies. Just as these buildings often conserve history or culture, the buildings themselves are increasingly seen 


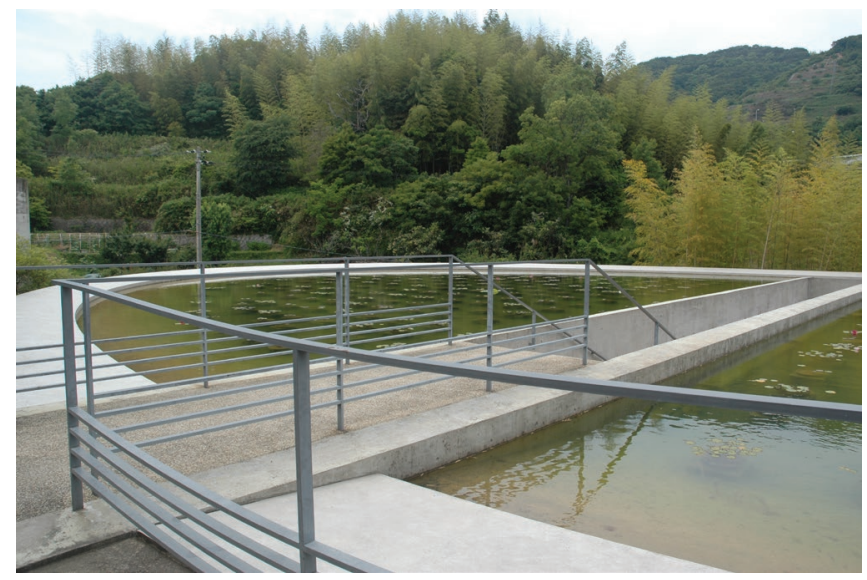

Figure 1. Water Temple, Hyogo, Japan, 1991. Copyright Liane Hancock, 2017.

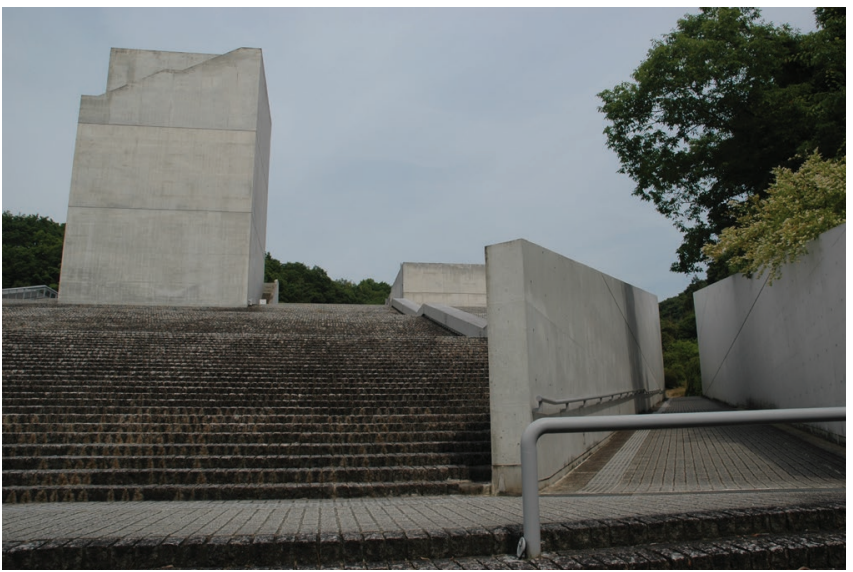

Figure 3. Chikatsu Asuka Museum, Osaka, Japan, 1994. Copyright Liane Hancock, 2017.

as monuments. Additionally, to emphasize their importance, internationally recognized architects often receive commissions for their design. Consequentially, the buildings are viewed as requiring preservation in perpetuity, but a consistent protocol by which to maintain these edifices does not exist. Building forever is not within the Japanese canon.

\section{PERMANENCE IN THE UNITED STATES}

The impermanence of Japanese architecture may surprise Westerners. After all, in Western civilization a person's home is their castle - and the myth is that a castle lasts forever. Conventional wisdom in the United States is that average life expectancy for a building is 100 years, $30 \%$ longer than life expectancy. But, with the advent of modernism this length has greatly decreased.

The decimation of World War II and the ensuing economic boom required quick innovative construction. Materials and assemblies were lauded for their cheapness; testing how they would behave in the environment or over the lifetime of the building simply was not a priority; the laboratory was the

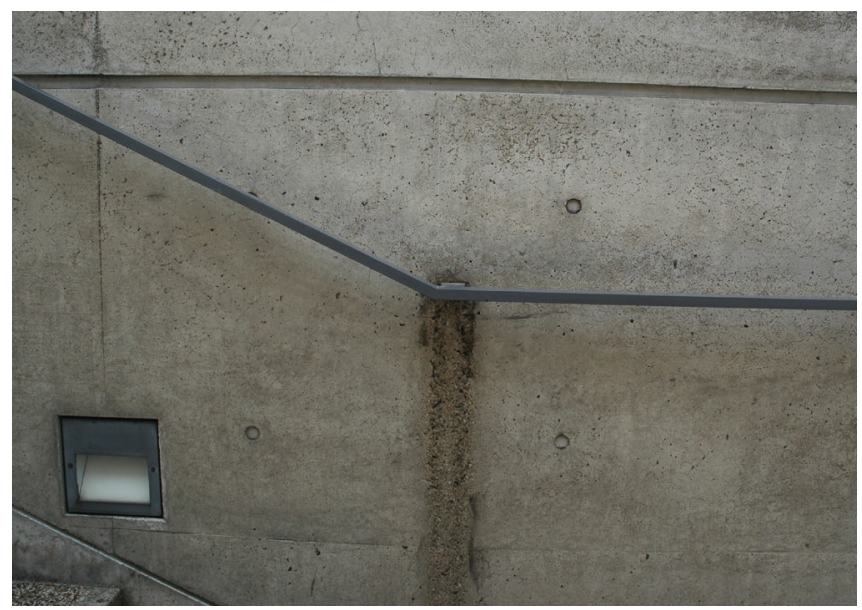

Figure 2. Water Temple, Hyogo, Japan, 1991. Copyright Liane Hancock, 2017.

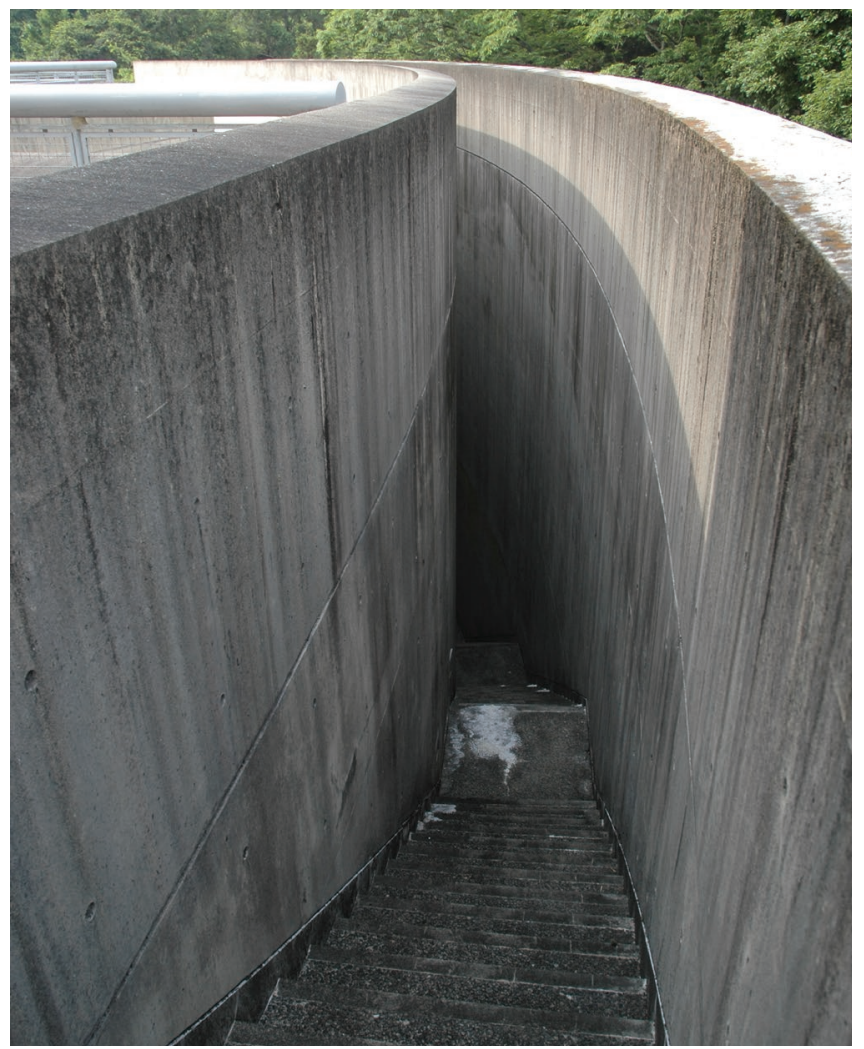

Figure 4. Chikatsu Asuka Museum, Osaka, Japan, 1994. Copyright Liane Hancock, 2017.

urban fabric, the study of material behavior occurred in situ in real time. Were modernist buildings supposed to grow old? To become historic? Or would they simply be replaced as newer materials and technologies became available? Concrete buildings are particularly symptomatic. Bad mix design, incorrect placement of reinforcement, and inaccurate vibration techniques led to poor installation. Initially seeming as permanent as stone, concrete quickly showed its age and fragility. 
During the Getty Center Colloquium to Advance the Practice of Preserving Modern Heritage, Kyle Normandin stated, "While heritage of the recent past has performed its intended program function for over fifty years, often technology has become obsolete while building standards become more stringent. Many building materials and systems of the Modern and postwar eras have reached the end of their physical and economic life span and require repair or replacement." 4

\section{AGING IN JAPAN}

Many of Tadao Ando's projects in Japan are twenty or thirty years old. Because maintenance has been largely unimportant in Japan, the pristine character associated with Ando's work has degraded. Concrete surfaces have suffered in particular. A hallmark of his work, when the surfaces are lost, a part of the architecture seems somehow lost too.

Across history, Japan has felt China's long shadow. For many decades, acid rain from coal-fired power plants has traveled from mainland China, blanketing Japan. In addition to effecting flora and fauna denitrification and sulfate absorption erode material surfaces, in particular stripping cement from the surface of concrete. This chemical action reveals the sand and rock aggregate that lays directly below. A building such as Ando's Water Temple in Hyogo Japan, built a mere twenty seven years ago, has lost its dense smooth surface in locations where rain water pools or runs down the surface of the building (figures 1 and 2). Once the surface is removed organic materials and inorganic pollution collects on the surface causing discoloration. For example, the pristine exterior surfaces of the Chikatsu Asuka museum, completed in 1994, now exhibit a definite patina (figures 3 and 4).

The marine environment of Japan exposes reinforced concrete constantly to airborne chloride. Depending upon the length of time the concrete remains moist, chloride from salt water in the air penetrates the surface. The acidic character gradually increases pore size on the surface; capillary absorption provides infiltration; and once deep enough steel reinforcing corrodes. Corroding steel provides internal pressure on the concrete, causing cracking. ${ }^{5}$ Consistent chloride exposure in conjunction with settlement has caused spalling in many of Ando's projects located along coastal Japan (figure 5).

In Japan, tradesmen have historically cast Ando's buildings in continuous pours. There are no expansion joints or control joints. The only delineation on the surface is the refined pattern left from the edges of the formwork. Within Japan, for many years, prevailing wisdom taught that uninterrupted reinforced concrete foundations were the best way to resist earthquakes. ${ }^{6}$ Additionally, control and expansion joints interrupt the aesthetic emphasis on the simple taut surface of Ando's architecture. Across Japan, buildings such as the Awaji Yumebutai Conference
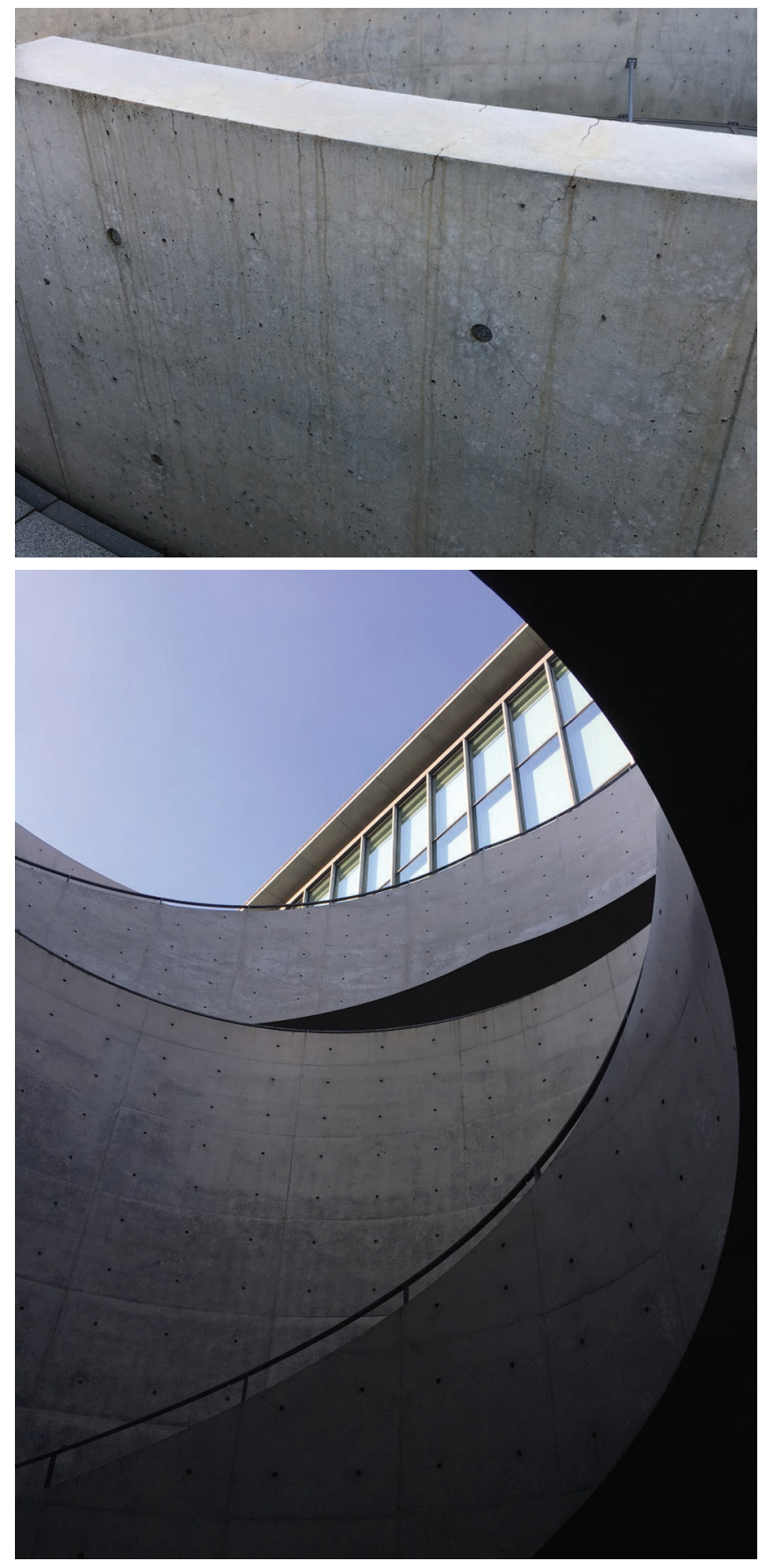

Figure 5. Hyogo Prefectural Museum of Art, Kobe, Japan, 2002. Copyright Liane Hancock, 2017.

Center, completed in 2000, show extensive cracking (figure 6). The site for the conference center was a quarry for Kansai Airport in Osaka Bay and Ando's enormous project extends across and caps the hillside. Without expansion or control joints, the concrete has failed in numerous locations. No attempts at preservation have been made. Over time, the conference center has grown less popular and in another decade a similar building, by an anonymous architect, would typically be demolished. 


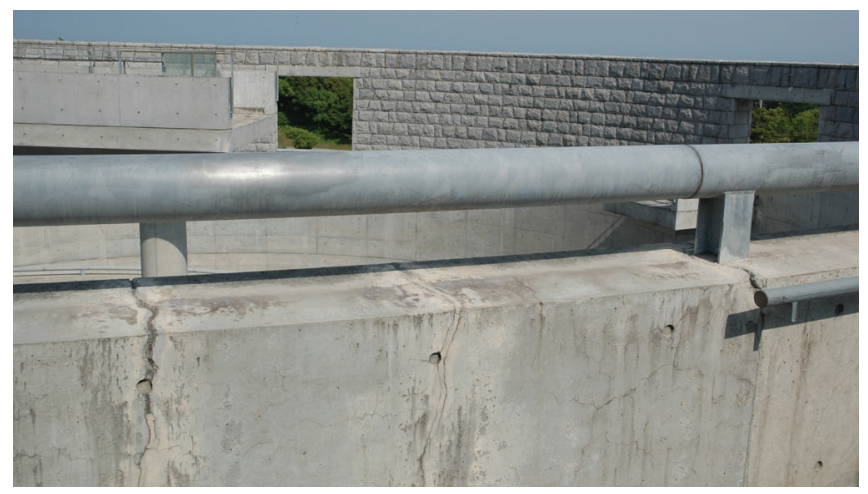

Figure 6. Awaji Yumebutai Conference Center, Awaji, Japan, 2000. Copyright Liane Hancock, 2017.

\section{KEEPING THE PULITZER AGELESS}

The Pulitzer was completed in 2001; today it still appears new and maintains relevancy. Its inland location, combined with limited air pollution results is far less threat of environmental degradation than Tadao Ando's buildings in Japan. Additionally, the engineering team required expansion and control joints, plus a system of seismic isolation - limiting cracking in the building. A robust maintenance protocol along with reliance upon the building's hidden flexibility means the building has not been compromised in its nearly twenty years of existence. During these two decades, the Foundation's mission significantly transformed to become an institution that is vital to the city. Originally a place to exhibit the Pulitzer family's art, it is now hosts rotating exhibits and extensive public events which support and actively engage the community.

\section{MAINTAINING THE CONCRETE}

The concrete on the Pulitzer building today is not the same concrete that was there when we finished the building. It evolves, it changes. The color changes, the texture changes. What we do know is that we can control the erosion and that we must slow it down.

-Steve Morby, Project Superintendent and Former Facilities Manager for the Pulitzer Arts Foundation, Interview

On a building this durable it is difficult to conceptualize that the smooth outer surface is only a fragile layer of cement paste. If unprotected, wind, sun, and weather could easily erode that layer. To maintain Ando's characteristic smooth surface in perpetuity, the design and construction team developed a sealant protocol very early in the design process. The sealant protocol began with a curing compound applied directly after stripping the formwork. Next the team applied a cyloxine sealer with a silicone base as a two week bridge sealer. Because the walls were still curing there was too much water in the walls to allow full penetration, but the surfaces were protected. The final sealer was then applied: pure silicone. As Steve Morby explains, "A silicone molecule is $1 / 10$ th of the size of a water molecule. As the water evaporated from the surface of the wall, microscopic holes the size of water molecules were left. The silicone bonded with the Portland cement. This made the holes 9/10th the size of a water molecule. By decreasing the size the water molecules could not fit any more. There was no room. If you sprayed the wall with water it just beaded on the surface."

After completion of the building, the Pulitzer adopted an ongoing maintenance sealer protocol using a latex based sacrificial graffiti sealer designed for stone. The sealer protects against any kind of foreign materials on the surface and provides UV and weather protection. Initially the sealer was to be applied every five years, but because the Pulitzer's surface is so dense the sealer could not penetrate as deeply as it did in the manufacturer's laboratory testing. The concern over preserving the surface has been so serious that the entire building is sealed each year (figure 7).

During the history of the building there have been instances where the surface of a wall has been damaged. In one case, lightning struck the building. After salvaging the pieces the area was reconstructed. By embedding the pieces in silicone caulk they could be reassembled, and paint blended the colors to match. Today, the patch is invisible to the naked eye.

On the interior, the columns and some of the walls are also concrete. These surfaces have never been sealed. Their smoothness attracts the touch irresistibly. To date, no attempt has been made at removing the residual hand oils. If the walls require cleaning the very surface that attracts touching may be damaged while removing the lingering effects of that intimacy.

From the years of touching there's a lot of oil from skin that's been put on the walls.

-Steve Morby, Interview

\section{PREVENTATIVE MAINTENANCE AND CHANGES TO SYSTEMS}

We approached preventative maintenance like a long term experiment. What happens if you were given the resources to maintain equipment the way it was supposed to be?

-Steve Morby, Interview ${ }^{8}$

Typically, when a building is handed over to the owner what has been learned by the design and construction team is quickly lost. While the owner receives as-built drawings, specific information on the building's behavior can be leveraged into 


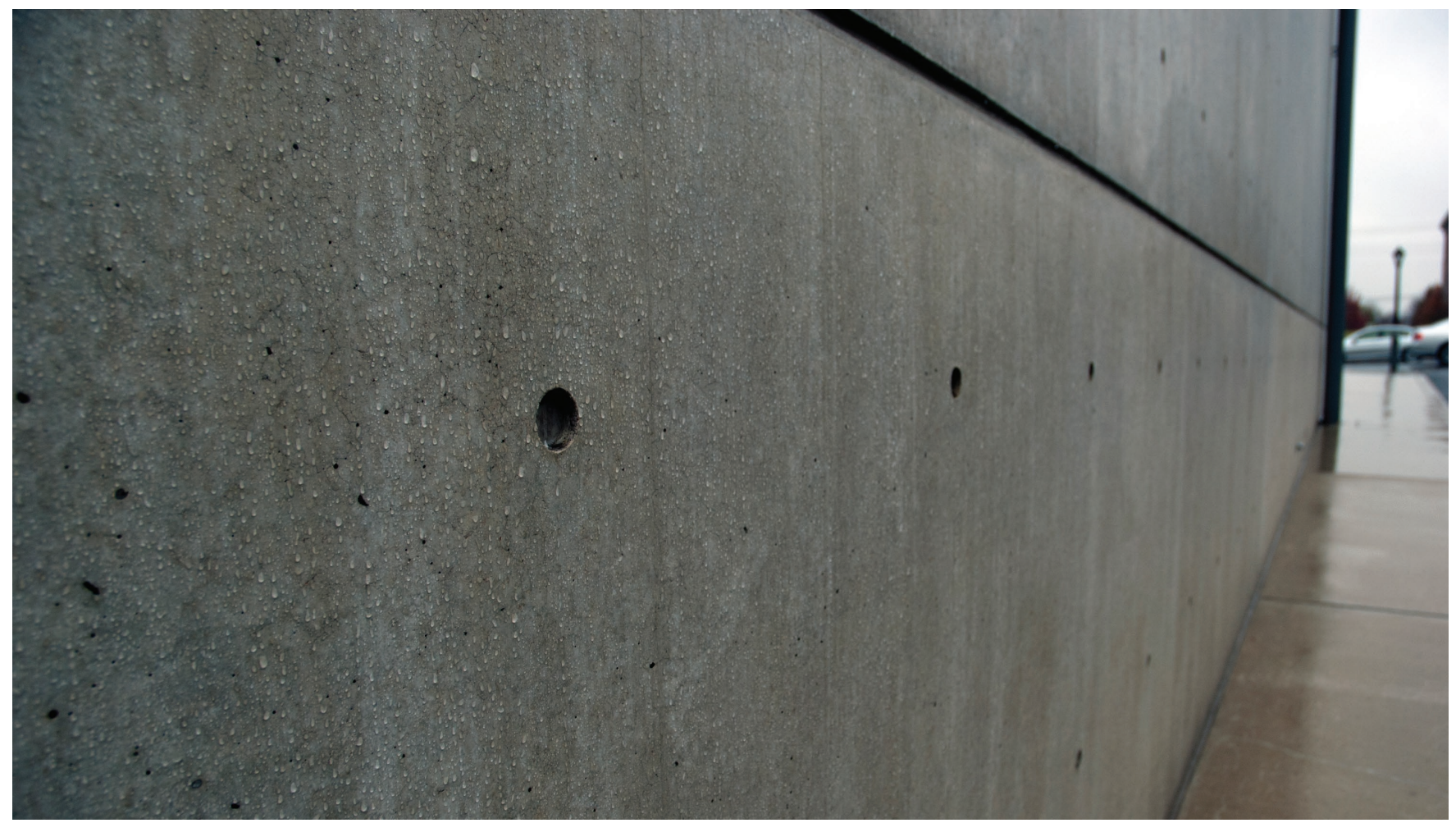

Figure 7. Pulitzer Arts Foundation, water being repelled by sealer. Copyright Liane Hancock.

liability, so as soon as the warranty ends it is best to forget that information as quickly as possible. When Emily Rauh Pulitzer selected Steve Morby as facilities manager, she created a seamless continuum where knowledge of the construction process could inform and enhance building operation. Maintaining the laboratory like research and testing processes developed during construction, building operation could be seen as something that could be tested and queried. How long would a piece of equipment run if it were properly maintained? How did it specifically operate-beyond what was stated in the service manuals? Was it as adjustable and resilient as had been advertised? By maintaining the equipment carefully, much of it continued to run past its expected lifetime. Additionally, some of the equipment provided greater agility than was initially expected.

The Pulitzer must maintain a very stable and safe interior in order to preserve exhibit materials including careful control of the interior environment, lighting, and security. Insurers require extensive historical data to confirm that control of the exhibition environment. Additionally, as the foundation's mission developed, it became clear that the building would be far more public than initially conceived. With greater number of people threat to the works increased. In less than twenty years of operation security systems, fire suppression systems, heating and air-conditioning have all been upgraded or replaced. The technology changed rapidly and maintaining a state of the art facility has kept the building's environment controlled.
Changes included camera surveillance systems and upgrades to heating and air conditioning system responding to greater changes in air and humidity infiltration now that the building has been open for more events. Just as we added redundancy into the building, with the building management system we added capacity - providing room for the foundation to grow and change in its needs. At the same time each system maintains autonomy, so that if one system stopped working, the rest of the building could still function.

-Steve Morby

\section{EXHIBITIONS}

In its new role, the foundation became a place to exhibit a wide range of artists and materials. The curators had to rely upon the building's adaptability to make it look as if those installations were effortless. The Pulitzer is a concrete box, with concrete floors, and plaster walls. The ceilings are constructed without soffits. To achieve these installations, the team had to consider where flexibility existed inside this seemingly inflexible box.

Understanding the specifics of the buildings construction has been key to creativity in installation. Because Tadao Ando had not yet completed the drawings of the upper levels of the building as the foundation and lower levels were being 
poured, the design and construction team added redundancy in chases and infrastructure: it was simply unclear where the mechanical, electrical, plumbing and fire suppression systems would be routed. That redundancy, in conjunction with a knowledge of the building, has provided flexibility to install a wide range of exhibits.

In order to create that effortless in exhibition, time and again we have had to test the versatility of the building. Adaptability, that's the Pulitzer. You would think that it is as rigid as stone! The trick is to manipulate the adjustability before it was 'Set in Stone.'

-Steve Morby, Interview ${ }^{9}$

In 2008, the Pulitzer exhibited Dan Flavin: Constructed Light. Over a dozen light displays were installed, and each one was located in a place that had no obvious power supply. There were no outlets built into the walls; they were solely in the ceiling track lighting and floor troughs. Looking at the building, it would seem impossible to install such an exhibit, but the team knew what was beneath the surface of the walls.

On the east wall, of the main gallery there were over ninety four foot fluorescent lights stacked tandem, starting at the floor and elevating by the width of the housing of the light, along each length of the housing. Adjacent to the elevator the installation was aligned with the floor, as it progressed across the wall it gained twelve feet in height. Understanding how the HVAC system was designed, we breached the cold air returns in the wall three times, dropping the circuits down into the boiler room below. For the other installations, there were many chases that were not shown on drawings that became very handy as we moved between floors.

-Steve Morby, Interview ${ }^{10}$

\section{CONCLUSION}

The Pulitzer Arts Foundation appears ageless. The neighborhood surrounding it has developed precipitously emboldened by this institution's presence and involvement. A still gleaming building, the Pulitzer has always stood for what the neighborhood could be. Fundamental to achieving this, the foundation has approached maintenance and change with the same laboratory-like attitude that was established during the design and construction process. A spirit of testing and innovation in problem solving, in conjunction with emphasis on redundancy and adaptability, has fundamentally driven decision-making.

Even though Westerners believe buildings are permanent, fundamentally buildings are always in a state of flux - whether that is deterioration of materials overtime, incorporation of advancements in technology, or alteration of programmatic vision. These changes are inevitable. The approach by which designers and owners accommodate these changes should be considered even as the building is being designed. The Pulitzer Arts Foundation presents a case study: what happens when the owner and staff are willing to dedicate resources and out of the box thinking for maintenance and adaption within the building? The work required for upkeep and adaptability is invisible; and the building remains forever new.

This paper derives much of its content from interviews with Steve Morby, project superintendent and former facilities manager for the Pulitzer Arts Foundation. Liane Hancock and Steve Morby will be co-authors on a forthcoming book on the Pulitzer Arts Foundation.

\section{ENDNOTES}

1 "Nobody's Home: Why Japanese Houses Have Such Limited Lifespans,"The Economist 426, no. 9083 (March 2018): 73.

2 Philip Brasor and Masako Tsubuki, “Japan's 30-year Building Shelf-Life is Not Quite True," Japan Times, March 31, 2014. https://www.japantimes.co.jp/ community/2014/03/31/how-tos/japans-30-year-building-shelf-life-is-notquite-true/\#.XFGrr81MFPY.

3 Brasor and Tsubuki, "Japan's 30-year Building Shelf-Life is Not Quite True."

4 Kyle Normandin, "Physical Conservation Challenges Facing Modern Architecture," in A Colloquium to Advance the Practice of Preserving Modern Heritage, The Getty Conservation Institute (Los Angeles: J. Paul Getty Trust, 2013), 43.

5 O. Troconis de Rincon et al., "Effect of the Marine Environment on Reinforced Concrete Durability in Iberoamerican Countries," Science Direct 49, no. 7 (July 2007): 2832-2843.

6 Dana Buntrock, correspondence, July 2018.

7 Steve Morby, interview, July 2011, St. Louis, MO.

8 Morby, interview.

9 Morby, interview.

10 Morby, interview.

11 Morby, interview.

12 Morby, interview.

13 Morby, interview. 